\title{
Fossil rewrites early human evolution
}

\author{
Ethiopian find dates back 4.4 million years.
}

A 17-year investigation into a fossilized early human skeleton from Ethiopia culminated last week with 11 papers published in Science.

Detailed descriptions of the skeleton, of a fairly complete 4.4-million-year-old female, show that humans did not evolve from ancient knuckle-walking chimpanzees, as has long been believed. The new fossils of Ardipithecus ramidus - known as 'Ardi' - offer the first substantial view of the biology of a species close to the time of the last common ancestor shared by humans and apes. Like modern humans, Ardi could walk upright (see depiction, right) and didn't use her arms for walking, as chimps do. Still, she retains a primitive big toe that could grasp a tree like an ape ${ }^{1}$.

Previously, the oldest near-complete skeleton of an early human was the 3.2-millionyear-old Australopithecus afarensis skeleton known as Lucy, also from Ethiopia. Because Lucy had many traits in common with modern humans, she didn't provide much of a picture of the earlier lineage between apes and humans, says Alan Walker, a biological anthropologist at Pennsylvania State University in University Park. The new A. ramidus "is so much more important — and strange”, he says.

The earliest Ardipithecus, A. kadabba, lived around 5.8 million years ago in Ethiopia ${ }^{2}$. The other oldest known hominids are Orrorin tugenensis, from about 6 million years ago in Kenya ${ }^{3}$, and Sahelanthropus tchadensis, from at least 6 million years ago in $\mathrm{Chad}^{4}$ (see graphic).

In addition to describing the fossils, the Science papers provide details about the geol- ogy and palaeoenvironment of the discovery site, in the Afar desert 230 kilometres northeast of Addis Ababa. The research team, known as the Middle Awash Project, involves 70 investigators, 47 of whom are authors on the papers.

In 1992, team member Gen Suwa found the first specimen of $A$. ramidus near the Ethiopian village of Aramis. Within two years, enough fossils had been found to produce the first article that named and sketchily described the animal, from a total of 17 fossils ${ }^{5}$.

Some researchers have complained how long it has taken to publish work about the fossils. But Berhane Asfaw, a co-director of the Middle Awash Project at the Rift Valley Research Service in Addis Ababa, says: "We weren't interested in how many papers we could publish. Our interest was in the full chain of information; that produces the power of the work."

From more than 135,000 vertebrate bone or tooth pieces, the team identified 110 as being from $A$. ramidus, representing a minimum of 36 individuals. The fossils come from a sediment layer sandwiched between two layers of volcanic rock known as tuff - each dated to 4.4 million years ago, says a team led by Giday WoldeGabriel, of Los Alamos National Laboratory in New Mexico. Fossils in the sediments include plants, pollen, invertebrates and birds, which helped to pinpoint the woodland environment where Ardi lived.
Years of field work uncovered Ardi's skull, teeth, arms, hands, pelvis, legs and feet - all of which had to be painstakingly prepared. Ardi's skull was recovered crushed in more than 60 pieces that were broken and scattered about. The bone was poorly fossilized - so soft that each piece had to be moulded in a silicon rubber cast then digitized by computed tomography scans.

Ardi's hands and wrists don't show several distinctive chimp characteristics, such as some larger bones and a tendon 'shock absorber' system to withstand bodyweight, says team member Owen Lovejoy of Kent State University in Ohio. The foot, with its big toe sticking out sideways, would have allowed Ardi to clamber in trees, walking along branches on her palms. And her teeth show no tusk-like upper canines, which most apes have for weapons or display during conflict. "This is a major feature showing that Ardi is not in the lineage of modern chimps," Suwa says.

\section{Rex Dalton}

1. White, T. D. et al. Science 326, 75-86 (2009)

2. Haile-Selassie, Y. Nature 412, 178-181 (2001)

3. Senut, B. et al. C. R. Acad. Sci. Paris Ser. Ila 332, 137-144 (2001).

4. Brunet, M. et al. Nature 418,145-151 (2002).

5. White, T. D., Suwa, G. \& Asfaw, B. Nature 371, 306-312 (1994).

\section{For a longer version of this story, see} go.nature.com/gSAuY5

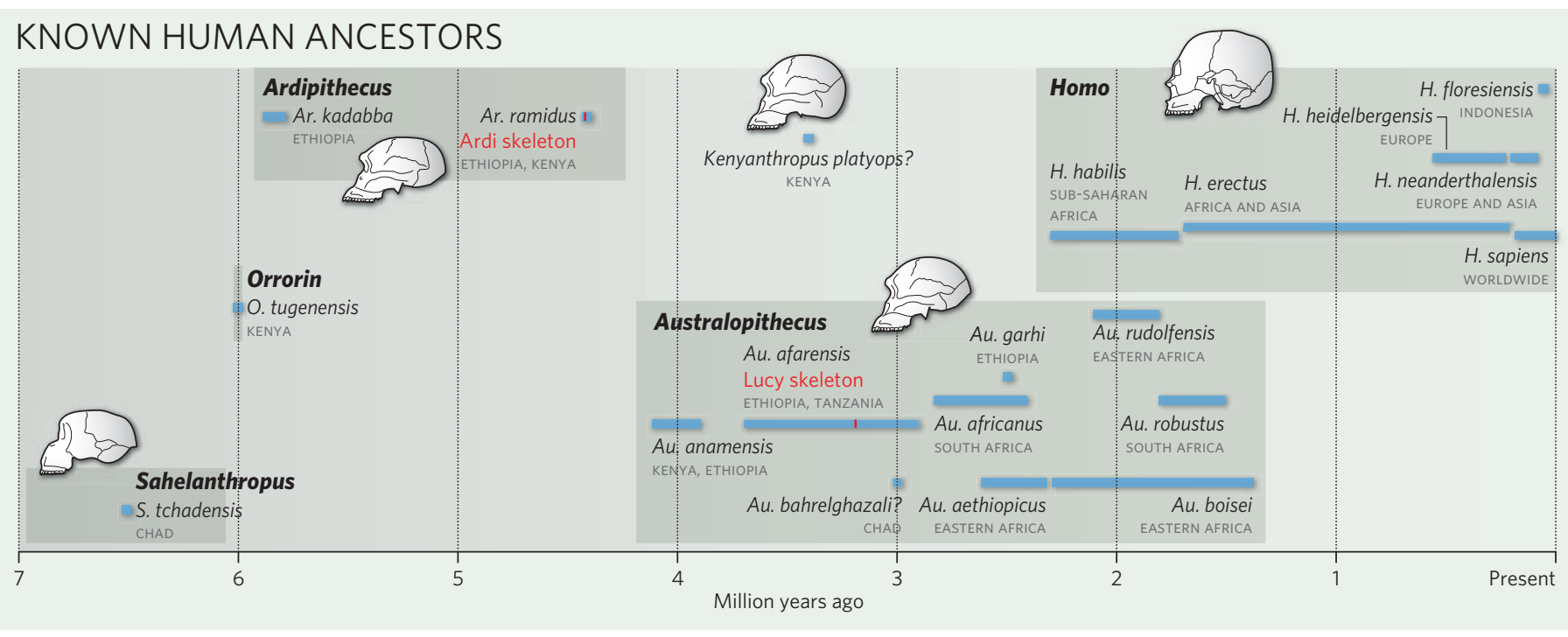

